\title{
PEMISAHAN DAN IDENTIFIKASI EKSTRAK KASAR SESKUITERPEN DAUN BUNGA MATAHARI (Helianyhus annuus L.) DENGAN KROMATOGRAFI LAPIS TIPIS
}

\author{
Roihatul Muti'ah, Elok Kamilah Hayati, Yani Triastutik
}

Jurusan Kimia, Fakultas Sains dan Teknologi UIN Maulana Malik Ibrahim Malang

\begin{abstract}
The purpose of this research wasto separate and identify the leaf crude extracts esquiterpene of Sun flower (Helianthus annuus L.) using thin layer chromatography.

Sun flower leaf maceration method performed with the solvent methanol. Then performed liquid extraction with ethyl acetate and n-hexane solvent. Ethyl acetate extract fraction and n-hexane extract fraction furth erphyto chemical test. After being test edphyto chemical with reagents, both extracts was followed by sesquiterpene content identification using thin layer chromatography (TLC) analytic.

Phytochemical test result from ethyl acetate extract fraction was positive terpenoid, sesquiterpene and triterpene, while $\mathrm{n}$-hexane extractfraction positive terpenoid, sesquiterpene andsteroid. All egedsesquiterpene with eluentdichloromethane: ethyl acetate $(4,8: 0,2)$ is shown with apurplestain. In the ethyl acetate extract fraction all egedsesquiterpene having Rf values of $0.89 ; 0.94$, and 0.96 . While $\mathrm{n}$-hexane extract fraction, the resulting eluental legedsesquiterpene $\mathrm{Rf} 0.49 ; 0.8$, and 0.99 .
\end{abstract}

Key word: Helianthus annuus L., sesquiterpene, phytochemicaltest, TLC

\section{PENDAHULUAN}

Malaria merupakan suatu penyakit yang disebabkan oleh parasit Plasmodium yang ditularkan ke manusia melalui gigitan nyamuk yang terinfeksi tersebut. Plasmodium falciparum dan Plasmodium vivax merupakan jenis malaria yang paling sering dijumpai, namun yang paling mematikan adalah Plasmodium falciparum (WHO, 2006).

Berbagai upaya telah dilakukan untuk mengurangi permasalahan tersebut, salah satunya dengan pemberian obat antimalaria. Salah satu tumbuhan yang digunakan masyarakat sebagai obat antimalaria adalah daun Bunga Matahari (Wijayakusuma, 2000).

Penelitian yang dilakukan oleh Triastutik (2013) melaporkan bahwa ekstrak kasar seskuiterpen fraksi etil asetat dan fraksi n-heksana memiliki potensi sebagai antimalaria. Dosis terbaik untuk ekstrak fraksi etil asetat adalah $0,4 \mathrm{mg} / \mathrm{g}$ BB dengan rata-rata persen penghambatan pada hari ke-4 sebesar 72,78\%. Sedangkan untuk ekstrak fraksi n-heksana dosis terbaiknya adalah $0,004 \mathrm{mg} / \mathrm{g}$ BB dengan rata-rata persen penghambatan pada hari ke-4 pasca terapi sebesar 71,51 \%. Kandungan senyawa yang ada pada kedua ekstrak ditunjukkan dengan adanya hasil uji reagen yang menunjukkan bahwa ekstrak fraksi etil asetat dan ekstrak fraksi nheksana positif seskuiterpen.

Penelitian yang dilakukan Bayyinah (2012) diketahui bahwa ekstrak diklorometan daun Bunga Matahari (Helianthus annuus L.) memiliki tingkat aktivitas antimalaria terhadap hewan uji dengan persen penghambatan pada hari keempat sebesar $100 \%$ untuk dosis 0,05 $\mathrm{mg} / \mathrm{g} \mathrm{BB}, 0,5 \mathrm{mg} / \mathrm{g}$ BB dan dosis $5 \mathrm{mg} / \mathrm{g}$ BB. Hasil pemisahan ekstrak diklorometan daun Bunga Matahari dari KLTP yang diidentifikasi menggunakan UV-Vis dan FTIR menunjukkan bahwa ekstrak diklorometan mengandung senyawa steroid dan seskuiterpen lakton.

Berdasarkan beberapa penelitian tersebut, maka dilakukan identifikasi dan pemisahan kandungan senyawa aktif seskuiterpen menggunakan kromatografi lapis tipis analitik dengan berbagai macam variasi eluen. 


\section{METODE PENELITIAN Alat dan Bahan Penelitian}

Alat-alat yang digunakan pada penelitian ini adalah seperangkat alat gelas, rotary evaporator, neraca analitik, kertas saring, plat KLT silika gel $60 \mathrm{~F}_{254}$, bejana pengembang, lampu UV, pipa kapiler, penyaring buchner, dan shake.

Bahan yang digunakan meliputi daun Bunga Matahari,metanol, etil asetat, nheksana, petroleum eter, asam asetat anhidrat, asam sulfat $\left(\mathrm{H}_{2} \mathrm{SO}_{4}\right)$ pekat, kloroform, benzena, aseton, pereaksi vanilin-asam sulfat,iodium, aquades.

\section{PROSEDUR PENELITIAN}

\section{Preparasi Sampel}

Seluruh bagian dari daun Bunga Matahari dicuci dengan air, kemudian dipotong kecil-kecil, sampel dikeringkan dengan oven pada suhu $27-37{ }^{\circ} \mathrm{C}$ selama 5 hari (Hernani dan Nurdjanah, 2009). Setelah itu, diblender sampai berbentuk serbuk.

\section{Ekstraksi Golongan Senyawa Seskuiterpen dari Daun Bunga Matahari Serbuk daun Bunga Matahari} ditimbang sebanyak 150 gr, untuk mengoptimalkan proses ekstraksi, sampel diekstrak dalam dua tempat dan masingmasing jumlah sampel adalah 75 gr. Kemudian masing-masing sampel dimaserasi menggunakan $300 \mathrm{~mL}$ pelarut metanol selama 24 jam dengan bantuan pengocokan selama 3 jam menggunakan shaker. Kemudian disaring dan ampas yang diperoleh dari masing-masing sampel direndam kembali dengan $300 \mathrm{~mL}$ pelarut metanol hingga diperoleh filtrat yang berwarna lebih bening.Ekstrak yang diperoleh kemudian digabungkan dan dipekatkan dengan rotary evaporator sampai diperoleh ekstrak pekat metanol dan ditimbang.Ekstrak pekat metanol selanjutnya dipartisi dengan menggunakan pelarut etil asetat dan pelarut n-heksana.

\section{Uji Fitokimia}

\section{Uji Terpenoid}

Ekstrak diambil sedikit kemudian ditambahkan $2 \mathrm{~mL}$ kloroform. Selanjutnya ditambahkan $3 \mathrm{~mL}$ asam sulfat secara perlahan hingga terbentuk lapisan berwarna. Warna merah kecoklatan menunjukkan positif terpenoid (Trease and Evans, 2002).

\section{Uji Seskuiterpen}

Uji seskuiterpen dilakukan dengan melarutkan ekstrak dalam petroleum eter, kemudian diuapkan hingga kering, dan ekstrak pekat yang dihasilkan ditambah dengan pereaksi vanillin $10 \%$ dalam asam sulfat. Hasilnya adalah larutan yang menghasilkan warna-warna (Farnsworth, 1966).

\section{Uji Triterpen/Steroid}

Ekstrak diambil $5 \mathrm{mg}$, dilarutkan dalam 0,5 mL kloroform lalu ditambahkan $0,5 \mathrm{~mL}$ asam asetat anhidrida dan $0,5-1 \mathrm{~mL}$ asam sulfat pekat melalui dinding tabung.Jika terbentuk warna biru sampai hijau, menunjukkan adanya steroid, sedangkan jika hasil yang diperoleh berupa cincin kecoklatan atau violet pada perbatasan dua pelarut menunjukkan adanya triterpen (Auterhoff and Kovar, 1987).

\section{Kromatografi Lapis Tipis Analitik}

Pada identifikasi dengan

KLTdigunakan plat silika gel $60 \mathrm{~F}_{254}$ yang sudah diaktifkan dengan pemanasan dalam oven pada suhu $100^{\circ} \mathrm{C}$ selama 30 menit. Masing-masing plat tersebut dipotong dengan ukuran $1 \mathrm{~cm}$ x $10 \mathrm{~cm}$. Ekstrak fraksi etil asetat dan ekstrak fraksi n-heksana ditotolkan sebanyak 0,04 gr yang dilarutkan dalam $3 \mathrm{~mL}$ pelarutnya masing-masing pada jarak $\pm 1 \mathrm{~cm}$ dari tepi bawah plat dengan pipa kapiler. Noda/bercak hasil pemisahan kemudian diamati di bawah sinar UV pada panjang gelombang $254 \mathrm{~nm}$ dan $366 \mathrm{~nm}$.Beberapa variasi eluen yang digunakan untuk identifikasi kandungan senyawa seskuiterpen pada ekstrak fraksi 
etil asetat dan ekstrak fraksi n-heksana ditunjukkan pada Tabel 1.

Tabel 1. Jenis-jenis fase gerak dan pendeteksi untuk metabolit sekunder seskuiterpen pada uji KLT

\begin{tabular}{|c|c|c|}
\hline Fase Gerak & Pendeteksi & $\begin{array}{c}\text { Hasil } \\
\text { Warna } \\
\text { Noda }\end{array}$ \\
\hline $\begin{array}{l}\text { Aseton:n-heksana } \\
(3: 10)\end{array}$ & \multirow{6}{*}{$\begin{array}{l}\text { Larutan } \\
\text { iodium }\end{array}$} & \multirow{6}{*}{$\begin{array}{l}\text { Bercak } \\
\text { coklat }\end{array}$} \\
\hline $\begin{array}{c}\text { Kloroform:petroleum } \\
\text { eter }(4: 1)\end{array}$ & & \\
\hline Benzena:aseton (4:1) & & \\
\hline $\begin{array}{c}\text { Benzena:metanol } \\
(9: 1)\end{array}$ & & \\
\hline $\begin{array}{c}\text { Benzena:petroleum } \\
\text { eter }(2: 3)\end{array}$ & & \\
\hline $\begin{array}{c}\text { Petroleum } \\
\text { eter:kloroform:etil } \\
\text { asetat }(2: 2: 1)\end{array}$ & & \\
\hline $\begin{array}{l}\text { Diklorometana: etil } \\
\text { asetat }(4,8: 0,2)\end{array}$ & \multirow{4}{*}{$\begin{array}{c}\text { Pereaksi } \\
\text { vanilin-asam } \\
\text { sulfat }\end{array}$} & \multirow{4}{*}{ Ungu } \\
\hline $\begin{array}{c}\text { Etil asetat: } n- \\
\text { heksana }(3: 97)\end{array}$ & & \\
\hline $\begin{array}{c}\text { n-heksana:etil asetat } \\
(4: 1)\end{array}$ & & \\
\hline Kloroform $100 \%$ & & \\
\hline $\begin{array}{l}\text { Kloroform:metanol } \\
\qquad(9: 1)\end{array}$ & $\begin{array}{l}\text { Penyemprot } \\
\text { asam sulfat }\end{array}$ & $\begin{array}{c}\text { Hijau, } \\
\text { coklat, } \\
\text { kuning, } \\
\text { atau } \\
\text { biru }\end{array}$ \\
\hline
\end{tabular}

\section{HASIL DAN PEMBAHASAN Preparasi Sampel}

Daun Bunga Matahari kering dihaluskan sampai menjadi serbuk.Sampel yang telah kering dengan warna hijau kecoklatan. Sampel diserbukkan dimaksudkan untuk memperluas permukaan dari bahan sehingga proses ekstraksi akan lebih mudah dan senyawa yang terekstrak lebih maksimal.

\section{Ekstraksi Golongan Senyawa Seskuiterpen dari Daun Bunga Matahari}

Ekstraksi maserasi dilakukan dengan mengambil sampel sebanyak 150 gram dan diekstraksi dengan metanol $2400 \mathrm{~mL}$. Selama proses perendaman dilakukan pengadukan dengan bantuan shaker selama
3 jam. Pengadukan dilakukan dengan tujuan agar terjadi banyak kontak antara pelarut dengan sampel sehingga akan mempercepat proses ekstraksi. Perendaman dihentikan ketika filtrat telah berubah menjadi pucat.Pucatnya filtrat dapat dianggap bahwa semua senyawa yang berbobot molekul rendah telah terekstrak (Harborne, 1987). Sampel yang telah terekstrak selanjutnya disaring dengan bantuan corong buchner untuk memisahkan antara filtrat dengan residu. Filtrat yang telah selanjutnya dipekatkan dengan bantuan rotary evaporator vaccum. Rendemen ekstrak pekat metanol yang diperoleh sebesar 16,3401\%.

Ekstrak pekat metanol selajutnya dipartisi dengan etil asetat.Ekstrak pekat metanol dilarutkan dengan metanol-air (1:9) yang kemudian dipartisi dengan etil asetat.Fraksi atas yang diperoleh merupakan ekstrak yang larut etil asetat dan fraksi bawah merupakan ekstrak yang larut dalam metanol-air. Penentuan fraksi bawah dan fraksi atas dilihat dari nilai berat jenis pelarut, untuk berat jenis metanol adalah $0,7915,1$ untuk berat jenis air dan 0,902 untuk berat jenis etil asetat. Partisi selanjutnya yaitu ekstrak pekat metanol yang dilarutkan dengan metanol dan kemudian dipartisi dengan n-heksana.Fraksi atas merupakan ekstrak yang larut nheksana dan fraksi bawah merupakan ekstrak yang larut metanol. Hasil dari partisi tersebut dipekatkan dengan rotary evaporator sehingga didapatkan rendemen ekstrak etil asetat sebesar 51,138\% dan ekstrak n-heksana sebesar 14,6426\%.

\section{Uji Fitokimia}

Uji fitokimia merupakan suatu tahapan pengamatan secara kualitatif untuk mengetahui kandungan metabolit sekunder suatu sampel.Pada penelitian ini hanya dilakukan uji terpenoid, seskuiterpen, dan triterpen/steroid.Hasil uji fitokimia dapat dilihat pada Tabel 2.

Tabel 2. Hasil identifikasi golongan senyawa ekstrak daun Bunga Matahari 


\begin{tabular}{|c|c|c|}
\hline Uji & Etil asetat & n-heksana \\
\hline Terpenoid & + & + \\
\hline Seskuiterpen & ++ & +++ \\
\hline Triterpen & ++ & - \\
\hline Steroid & - & +++ \\
\hline
\end{tabular}

Keterangan:

$+++\quad=$ Kandungan senyawa lebih banyak (warna sangat pekat)

$++\quad=$ Mengandung senyawa (warna cukup pekat)

$+\quad=$ Mengandung senyawa (berwarna)

- $\quad=$ Tidak terkandung senyawa

\section{Identifikasi Kandungan Senyawa Aktif dengan Kromatografi Lapis Tipis Analitik}

Kromatografi lapis tipis merupakan metode pemisahan senyawa kimia yang didasarkan pada dua fase yaitu fase gerak yang berupa cairan dan fase diam yang berupa padatan.

Eluen terbaik dalam identifikasi dan pemisahan senyawa seskuiterpen ekstrak fraksi etil asetat dan ekstrak fraksi nheksana adalah diklorometan:etil asetat $(4,8: 0,2)$ dengan pendeteksi vanilin-asam sulfat. Pada ekstrak fraksi etil asetat dihasilkan 6 noda dengan 3 noda berwarna ungu yang diduga sebagai senyawa seskuiterpen ( $\operatorname{Rf} 0,89$; 0,94 dan 0,96) dan ekstrak fraksi n-heksana dihasilkan 7 noda dengan 3 noda berwarna ungu yang diduga sebagai seskuiterpen $(\operatorname{Rf} 0,49 ; 0,8$ dan 0,99).Adapun hasil identifikasi KLT analitik ekstrak fraksi etil asetat dan ekstrak fraksi n-heksana setelah disemprot dengan vanilin-asam sulfat dan dideteksi dengan UV 366 nm ditunjukkan pada Gambar 1 .

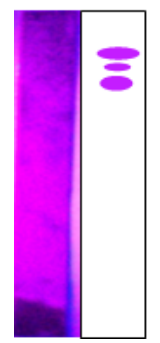

a

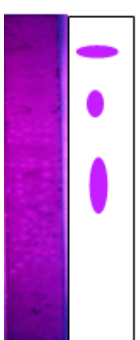

b
Keterangan :

a. Hasil identifikasi KLT analitik untuk ekstrak fraksi etil asetat

b. Hasil identifikasi KLT analitik untuk ekstrak fraksi n-heksana

\section{KESIMPULAN}

Berdasarkan hasil identifikasi dengan uji reagen diketahui bahwa ekstrak nheksana mengandung golongan senyawa steroid. Pemisahan dengan KLT menggunakan eluen n-heksana-etil asetat (8:2) menghasilkan 4 noda dengan nilai $\mathrm{Rf}$ berturut-turut 0,$10 ; 0,35 ; 0,61$; dan 0,68 .

\section{SARAN}

Perlu dilakukan pemisahan lebih murni dengan kromatografi kolom-KLTP dan hasil isolat yang dihasilkan diidentifikasi dengan instrumentasi MS.

\section{DAFTAR PUSTAKA}

Auterhoff, H., and Kovar, KA. 1987. Identifikasi Obat. Bandung: ITB.

Bayyinah, I. 2012. Identifkasi dan Uji Aktivitas Ekstrak Diklorometan Daun Bunga Matahari(Helianthus annuus L.)Sebagai Antimalaria Secara In Vivo Pada Mencit Jantan. Skripsi Tidak Diterbitkan. Malang: Jurusan Kimia Fakultas Sains dan Teknologi UIN Maliki Malang.

Farnsworth, N. R. 1966. Biological and Phytochemical Screening of Plants.Journal of Pharmaceutical Sciences March 1966. Volume: 55. Number 3: 243-269.

Harborne, JB. 1987. Metode Fitokimia Penuntun Cara Modern Menganalisis Tumbuhan. Penerjemah: Kosasih Padmawinata dan Iwang Soediro. Bandung: Penerbit ITB.

Hernani dan Nurdjanah, R. 2009.Aspek Pengeringan dalam Mempertahankan Kandungan Metabolit Sekunder pada Tanaman Obat.Perkembangan Teknologi TRO 21 (2), ISSN 18296289. Bogor: Balai Besar Penelitian dan Pengembangan Pascapanen Pertanian. 
Trease, GE. And Evans, WC. 2002. Pharmacology, $15^{\text {th }} \mathrm{Ed}$. Saunders Publishers. London.

Triastutik, Y. 2013. Aktivitas Antimalaria Ekstrak Kasar Seskuiterpen dari Daun Bunga Matahari (Helianthus annuus L.) Terhadap Mencit Jantan (Mus musculus). Skripsi Tidak Diterbitkan. Malang: Universitas Islam Negeri Maulana Malik Ibrahim Malang.
WHO. 2006. Guidelines for the Treatment of Malaria. http://www.who.int/malaria/publicati ons/atoz/9789241547925/en/index.ht $m l$ (Diunduh pada tanggal 25 Januari 2013).

Wijayakusuma, MH. 2000. Ensiklopedia Milenium: Tumbuhan Berkhasiat Obat Indonesia Bunga-Bungaan. Jakarta: Penerbit PT. Prestasi Insan Indonesia. 